\title{
LAS COMUNIDADES RURALES Y EL TURISMO COMUNITARIO EN LA ARGENTINA. LA PARTICIPACIÓN DEL ESTADO NACIONAL EN LA ACTIVIDAD (2003-2015). UN ANÁLISIS A MODO DE ENSAYO.
}

\author{
Lic. Carlos Juan Pedro Chiappe \\ Universidad Atlántida Argentina, \\ Universidad Nacional de Tres de Febrero \\ e Instituto Nacional de Asuntos Indígenas - \\ Ministerio de Justicia y Derechos Humanos.
}

\section{Resumen}

En este documento se realiza un análisis resumido del estado de desarrollo del Turismo Rural Comunitario en la Argentina y de la intervención del Estado nacional en la actividad hasta Diciembre de 2015 (fecha en que se produce el cambio de gobierno y de signo político y orientación de la gestión pública). Se presenta sintéticamente el trabajo conjunto y articulado de cuatro ministerios (de Turismo, de Trabajo y Seguridad Social, de Agricultura Ganadería y Pesca, y de Desarrollo Social), en relación con la dotación de instrumentos para el desarrollo sustentable del Turismo Rural Comunitario.

Palabras clave: Turismo Rural Comunitario - Comunidades Campesinas e Indígenas Actores Locales - Plan Federal Estratégico de Turismo Sustentable - Mesa Interministerial Cuatripartita - Desarrollo Sustentable. 


\title{
RURAL COMMUNITIES AND THE COMMUNITY TOURISM IN ARGENTI- NA. NATIONAL GOVERNMENT PARTICIPATION IN THE ACTIVITY (2003- 2015).
}

\author{
Lic. Carlos Juan Pedro Chiappe \\ Universidad Atlántida Argentina, \\ Universidad Nacional de Tres de Febrero \\ e Instituto Nacional de Asuntos Indígenas - \\ Ministerio de Justicia y Derechos Humanos.
}

\begin{abstract}
In this paper, an analysis of the state of development of Rural Community Tourism in Argentina, as well as the intervention of the national government in activity until December of 2015 is examined. The paper introduces the key elements related to programs, projects and activities to promote sustainable rural tourism, which conducted by four ministries: Tourism, Social Security, Agriculture, and Social Development.
\end{abstract}

Keywords: Rural Community Tourism - Farmers and Indigenous Communities - Local Actors - Federal Strategic Plan for Sustainable Tourism - Quadripartite Interministerial Committee - Sustainable Development. 


\section{Introducción}

En este trabajo, que no tiene otra pretensión que la descripción -con características ensayísticas- del desarrollo de una política pública asociada al turismo rural durante tres gestiones de gobierno en la Argentina (2003-2015) de las que hemos participado directamente, analizaremos como se vino gestionando esta actividad y qué resultados se alcanzaron hasta la fecha de cambio de gobierno y de signo político en Diciembre de 2015.

Comenzaremos trazando un sucinto panorama del desarrollo histórico, indicando que a partir de la década de 1950 el Turismo toma fuerte impulso como actividad de masas, en paralelo al desarrollo de políticas públicas tendientes a mejorar los niveles de calidad de vida de las poblaciones que sufrieron más directamente los efectos de la Segunda Guerra Mundial, básicamente en Europa y los Estados Unidos. La finalización de este conflicto implicó la necesidad de reconfigurar las prácticas capitalistas, adecuándolas al escenario de posguerra, retomando políticas económicas keynesianas de incremento de los niveles de consumo de los ciudadanos que dio lugar al llamado welfare state o estado de bienestar, asociado a los procesos de reconstrucción socio-territorial de los países afectados por la guerra.

Así como se produce en esta etapa en el mundo occidental una incorporación cada vez más amplia de habitantes al trabajo, alcanzando niveles muy elevados de ocupación total, el tiempo entre actividad y descanso comienza a exigir de una organización y reglamentación específicas que colaboren en apuntalar la reproducción y extensión del modo de producción capitalista, tomado en cuenta además las tensiones geopolíticas de la época asociadas a la dicotomía hegemónica entre este bloque y el socialista (guerra fría). Esta situación global fortalece la necesidad de establecer un ordenamiento del tiempo estructurado para el ocio de los trabajadores, garantizando, por una parte, el desarrollo capitalista sustentable de las actividades productivas $\mathrm{y}$, por otra, un instrumento para reducir las tensiones entre capital y trabajo. El estado de bienestar se extiende en general hasta principios del decenio de 1970, momento a partir del que el capitalismo adquiere un pulso diferente e instaura prácticas mucho más duras y restrictivas con relación a los derechos de los trabajadores, buscando aumentar la captación de recursos por vía del incremento de la productividad per cápita (con una importante reducción del número de asalariados, sobre todo en la década de 1990, junto con la precarización de las relaciones laborales en detrimento de éstos), del aumento de la inversión en capital fijo -sobre todo asociado a las nuevas tecnologías y a los sistemas informáticos-, por la transferencia de excedentes desde el tercer mundo y el retorno desigual de ganancias hacia las casas matrices de las empresas multinacionales, con sedes en los países dominantes, entre otros mecanismos de concentración económico-financiera. Según González Casanova se transfirieron de los países periféricos -los más pobres- a los más ricos, entre 1972 y 1976441.731 .000 .000 de dólares, monto que se multiplica tres veces para el quinquenio 1991-1995 (U\$S 1.364.405.000.000), acumulando pérdidas los pri- 
meros por 4.528.281.000.000 de dólares entre 1972 y 1995 (González Casanova, 1998).

Más allá de la evolución económica - general y del turismo en particular- de los últimos sesenta y cinco años que sintetizamos arriba, la actividad turística que se comienza a masivizar en los países hegemónicos desde 1950, ha ido creciendo casi constantemente en todo el mundo; si bien el mayor desarrollo lo ha tenido el turismo que podríamos definir como de matriz convencional, como por ejemplo los definidos como de sol y playa o el urbano, debemos referir que la modalidad de turismo alternativo, que se realiza en el ámbito rural, surge más o menos en la misma época. María Florencia Román y Mariana Ciccolella refieren que "el turismo rural surge de manera espontánea en los años cincuenta como una alternativa para recuperar las zonas rurales afectadas por la segunda guerra mundial" (Román y Ciccolella, 2009). Acercándonos hacia el presente, esta práctica turística incorpora conceptos provenientes de los avances del conocimiento de la naturaleza y la sociedad, así como de perspectivas políticas y económicas que buscan garantizar el desarrollo sustentable de ambas. Con la valorización del ambiente y los recursos naturales, así como del patrimonio cultural y de las identidades locales, comienza a darse un cambio en las perspectivas y políticas de desarrollo turístico, apareciendo un nuevo tipo de destinos turísticos y de turistas.

Además, desde hace un tiempo -sobre todo a partir de la década de 1990-, el Turismo al igual que otras actividades económicas en el marco del capitalismo dominante, ha buscado diversificarse para potenciar el negocio y maximizar ganancias. Sus formas tradicionales de desarrollo fueron resultando limitadas o insuficientes para el disfrute del ocio de un número cada vez mayor de turistas, así como se comienzan a detectar y definir formas alternativas de explotación económica, que también pueden generar ingresos y colaborar de manera suplementaria con las actividades rurales tradicionales, junto a una relativa generación de nuevas ocupaciones laborales en el campo. Más allá de que es cierto que aún el turismo de masas es el que concentra el mayor flujo económico y el número de turistas, hay un crecimiento importante de diferentes formas de turismo alternativo entre las que podemos destacar los llamados turismo rural comunitario, turismo comunitario, ecoturismo y otras modalidades.

A pesar de que la mayor parte de las voces, tanto en el ámbito de la gestión estatal y privada como en el de los estudios académicos, se pronuncia en favor de que el turismo rural es beneficioso para las comunidades y los territorios campesinos, hay otras miradas como la de José Antonio Segrelles quién sostiene que, en el marco del sistema capitalista con su lógica de búsqueda permanente de ganancias y de concentración en pocas manos de la riqueza socialmente producida, hay muchas dificultades para sostener "un equilibrio duradero entre las necesidades de la población, los recursos consumidos y las consecuencias ambientales de todo ello", refiriendo que éstas no son "sólo un problema científico-técnico, sino también sociopolítico y ético" (Segrelles, 2009). 
Tomando en cuenta que hay una perspectiva mayoritariamente positiva en relación a las actividades identificadas como de turismo rural, pero al mismo tiempo compartiendo en parte la opinión y análisis de Segrelles respecto a su desarrollo en el marco de la formación geo-histórica capitalista contemporánea, entendiendo que es difícil garantizar sustentabilidad y plena equidad socio-ambiental con el presente régimen de explotación económica de los recursos territoriales, a continuación haremos un racconto sintético de la situación en la que se encuentra el turismo rural comunitario (TRC de aquí en adelante) en nuestro país.

En relación con lo expresado, consideramos que la intervención del Estado en la planificación y gestión del TRC, en conjunto y acuerdo con las comunidades indígenas y campesinas y el sector privado, sin perder de vista la sustentabilidad y el equilibrio socio-ambiental y el marco socio-económico de desarrollo capitalista, puede y debe funcionar como instancia sinérgica positiva para el desarrollo territorial y la mejora de la calidad de vida de las poblaciones locales.

\section{Desarrollo}

Como decíamos previamente, el TRC ostenta no sólo un concepto positivo entre los organismos e instituciones públicas y privadas, sino que además se han llevado adelante políticas concretas de promoción de la actividad sustentadas desde el Estado argentino hasta Diciembre de 2015. Su surgimiento se asocia por un lado a la búsqueda de alternativas de ingresos por parte de agricultores y ganaderos frente a una crisis sectorial (Román y Ciccolella, 2009) y, por otro, a un aumento efectivo de la demanda de productos turísticos alternativos. En algunos países de América latina existen ejemplos de un importante desarrollo de esta modalidad; por ejemplo en México, Costa Rica, Chile y Guatemala, con la constitución de entidades internacionales como la Red de Turismo Rural Sostenible en América latina (REDTURS), mientras que en otros como por ejemplo Brasil, con extensos territorios y población rural, no hay una oferta suficiente de establecimientos de turismo rural para canalizar una potencial demanda, ya que el mercado se encuentra concentrado en manos de cadenas multinacionales de hotelería y grandes empresas, que lo explotan con altos márgenes de ganancia en la modalidad convencional dominante.

El desarrollo del TRC en nuestros países está vinculado con el ambiente (reservas, naturales, parques nacionales y provinciales, lagos, ríos, montañas) y con el contacto con culturas y actividades diferentes a las urbanas y de las del ocio convencional, tanto en comunidades campesinas como de pueblos originarios, recuperando la gastronomía típica y la producción artística y artesanal de los pobladores rurales, donde el valor principal del atractivo reside en el reconocimiento de las características singulares de cada grupo y lugar, así como la posibilidad de intercambio cultural con el que se busca promover en los visitantes la adquisición de nuevas experiencias y saberes sobre las comunidades anfitrionas. 
En la Argentina hay una variedad importante de ofertas de turismo rural, que no siempre son desarrolladas por actores sociales comunitarios o del sector agropecuario, para quienes resulta interesante y económicamente redituable esta alternativa de la actividad. Según un estudio realizado por la Facultad de Agronomía de la Universidad de Buenos Aires en el año 2012 (Dachary y Barrera, 2012), había en este momento alrededor de 1200 establecimientos de este tipo - cifra que este trabajo deja entrever a partir de la cantidad revelada por los autores de las direcciones de correo electrónico de éstos-. Los resultados obtenidos, que para los autores no conforman una muestra sino que responden a un criterio de encuesta (sobre 124 casos que respondieron a las consultas), indican que el $83 \%$ de los emprendimientos se iniciaron a partir del año 2001, y que para el $68 \%$ de quienes desarrollan esta actividad, la misma cubrió ( $42 \%$ ) o superó ( $26 \%$ ) sus expectativas, mientras que para el $32 \%$ restante los resultados fueron inferiores a los esperados. Entre las causas de esta última situación aparecen: la falta de publicidad de la actividad, problemas de acceso y falta de financiamiento, de formación para la comercialización y de políticas públicas locales. Respecto a aquellos elementos que operaron a favor de cumplir con las expectativas de los operadores de turismo rural, surgieron de la encuesta: el haber logrado ofrecer un producto diferenciado, su inserción en una ruta, la capacitación que les ofrece el Instituto Nacional de Tecnología Agropecuaria (INTA) a través de su Programa de Cambio Rural y otros instrumentos institucionales, el lograr vender una producción artesanal, saber comercializar y ofrecer una atención personalizada de los propietarios del emprendimiento.

Es interesante revisar esta encuesta, pues nos permite verificar algunas cuestiones que, con su resolución o mejora, podrían colaborar en la optimización de las condiciones generales de la actividad, beneficiando a los emprendedores turísticos rurales y comunitarios, sobre todo tomando en cuenta que el turismo es gran generador de empleo -más allá de la discusión sobre su calidad y sustentabilidad sobre la que hay muchos estudios realizados- y que, en la mayor parte de los casos, complementa las actividades tradicionales del campo.

El Estado argentino ha visibilizado esta situación y comenzado desde hace unos años a aportar distintos elementos dinamizadores del TRC. Los impulsos principales se han venido dando desde las Secretarías de Agricultura, Ganadería y Pesca y de Turismo de la Nación (hoy Ministerios), a través de diferentes programas y proyectos. Es de destacar la importancia territorial del Instituto Nacional de Tecnología Agropecuaria (INTA) en el acompañamiento de las comunidades y pobladores rurales para la promoción y el desarrollo de distintas actividades, entre ellas el turismo. Así el Estado nacional ha venido proveyendo asistencia financiera (préstamos y subsidios), fortalecimiento organizativo, colaboración técnica, capacitaciones, etc.

Con la presentación del Plan Federal Estratégico de Turismo Sustentable (PFETS) por parte del Ministerio de Turismo en Junio de 2005 (que hasta ese momento era Secretaría), se definen desde el Estado los lineamientos políticos por los que se proyecta que esta 
actividad transite en nuestro país, definiendo cuatro objetivos (ambientales, socioculturales, de calidad y socioeconómicos), y promoviendo distintos programas y proyectos específicos para el desarrollo del TRC: PROFODE (Programa de Fortalecimiento y Estímulo a Destinos Turísticos Emergentes), se crea la RATuRC (Red Argentina de Turismo Rural Comunitario), el Programa Argentino de Turismo Rural RAICES, y, en conjunto con el INTA y el Ministerio de Agricultura, Ganadería y Pesca de la Nación, el PRONATUR (Proyecto Nacional de Turismo Rural). Otros organismos nacionales públicos y privados también han venido trabajando en el ámbito rural en apoyo a las comunidades y pobladores en distintos aspectos, incluido el turístico, como por ejemplo el Ministerio de Desarrollo Social de la Nación a través de los Programas Manos a la Obra, Talleres Familiares, Mi Pueblo, Marca Colectiva, el Instituto Nacional de Asuntos Indígenas, etc.

Lo que hemos venido comentando de manera muy resumida, nos muestra una intervención del Estado Nacional a través de diferentes organismos de manera un tanto sesgada y desconectada. Esta ausencia de una sinergia en la planificación, aportes y gestión operativas no ha pasado desapercibida tanto entre los gestores públicos como entre los directos interesados, emprendedores o potenciales emprendedores turísticos, campesinos e indígenas. Es así que desde hace un poco más de dos años se ha conformado una Comisión de Trabajo Interministerial para el Desarrollo Turístico con Inclusión Social en el Espacio Rural y las Mesas Política y Técnica cuatripartitas, a partir de la firma del convenio marco de cooperación "Políticas Públicas para el Desarrollo del Turismo en el Espacio Rural de la República Argentina", entre los ministerios nacionales de Turismo, Trabajo, Empleo y Seguridad Social, Desarrollo Social y Agricultura, Ganadería y Pesca, que en el marco del PFETS y asociando esfuerzos y decisiones, trabajan en el territorio directamente con los desarrolladores turísticos rurales, avanzando en la integralidad turística de los abordajes. Esta perspectiva que entiende al Turismo como parte de un sistema en el que están actuando múltiples agentes y en el que acontecen diferentes situaciones al mismo tiempo y en los mismos lugares, necesariamente amplia el espectro de atención y acción, y obliga a articular la gestión política en el territorio, para garantizar, por una parte, el efectivo desarrollo de las propuestas turísticas seleccionadas y, por otra, garantizar que las mismas sean lo suficientemente coherentes y razonables de ejecutarse sustentablemente más allá de la intervención del Estado.

Las pautas requeridas para avanzar en la selección, el fortalecimiento y la creación de experiencias territoriales de turismo rural en el marco de la mesa cuatripartita, exigió que las mismas reunieran las siguientes características: que fueran realmente de TRC y asociativas, que debían estar acompañadas técnicamente, que respondieran a una demanda genuina o sentida comunitariamente, que tuvieran una mirada integral del territorio, que fortalecieran el capital social, fomentando la participación social, el asociativismo, el protagonismo de la mujer y de los jóvenes, apoyando el arraigo rural y el fortalecimiento de las organizaciones de productores y emprendedores, así como del trabajo de artistas 
y artesanos locales. Otra cuestión a la que estos proyectos debían responder era la de aprovechar las sinergias y colaborar en reinvertir el valor agregado local en el territorio, mejorando la calidad y la comercialización de las producciones regionales, así como al cuidado del ambiente y a la revalorización el patrimonio natural y cultural del medio rural. Se articuló con las instituciones presentes en el territorio (cooperativas, municipios, universidades, escuelas, ONGs, etc.). Además se hizo previamente una evaluación de la potencialidad turística real de cada propuesta y, una vez definida la misma, se comenzó con el desarrollo de la planificación y la gestión y seguimiento de los proyectos.

\section{Conclusiones}

Esta forma de trabajar implicó una nueva perspectiva desde la gestión pública, por medio de la cual se buscó potenciar los recursos del territorio, actuando conjuntamente áreas que antes lo abordaban por separado. Se propusieron acuerdos para el abordaje territorial y se organizaron comisiones conjuntas, en las que participaron técnicos y funcionarios de los cuatro ministerios que articularon con los emprendedores e instituciones locales, y definieron las necesidades y planificación para garantizar con diferentes recursos institucionales tanto el presente de cada emprendimiento como su sustentabilidad.

Con este diseño político se avanzó -hasta Diciembre de 2015- para fortalecer esta labor conjunta, en la que además de contar con la intervención de organismos públicos, apareció y se sumó un buen número de actores territoriales rurales, campesinos e indígenas, sumamente interesados en potenciar la actividad turística. La presencia del Estado, trabajando coherentemente y superando las diferencias funcionales para atender una demanda que, si bien se había venido atendiendo en forma parcial y dividida por áreas de gestión, pero que está siempre articulada sistémicamente en la realidad, buscó fortalecer la capacidad de resolver lo más abarcativamente posible las problemáticas locales del TRC y de promover fuertemente, con criterio sustentable, la actividad turística de matriz rural comunitaria. 


\section{Bibliografía}

Dachary, A. C. y Barrera, E. (2012). Sobre la situación del turismo rural en la República Argentina. Buenos Aires. Facultad de Agronomía, Universidad de Buenos Aires. Disponible en: http://www.agro.uba.ar/agro.

González Casanova, P. (1998). Reestructuración de las ciencias sociales: hacia un nuevo paradigma. México, CEIICH, UNAM, Colección Aprender a Aprender.

Román, M. F. y Ciccolella, M. (2009) Turismo rural en Argentina: concepto, situación y perspectivas. Buenos Aires, IICA. Segrelles, J. A.. (2009). Una reflexión sobre la insostenibilidad en el medio rural y natural. Los casos del ecoturismo y la ecología profunda. Versión ampliada el artículo del mismo título publicado en la revista Human Geography. A New Radical Journal, vol. 2, $\mathrm{N}^{\circ}$ 1, pp.103-113; ISSN: 1942-7786. 